\title{
Negative ion photoelectron spectroscopy of the copper-aspartic acid anion and its hydrated complexes
}

\author{
Xiang Li, Haopeng Wang, and Kit H. Bowen \\ Department of Chemistry, Johns Hopkins University, Baltimore, Maryland, 21218 \\ USA
}

Ana Martínez

Departamento de Materia Condensada y Criogenia. Instituto de Investigaciones en Materiales, Universidad Nacional Autónoma de México, Coyoacán, 04510, D.F. México

Jean-Yves Salpin

CNRS - Laboratoire Analyse et Modélisation pour la Biologie et l'Environnement UMR 8587 - Université d'Evry Val d'Essonne Bâtiment Maupertuis, Boulevard François Mitterrand, Evry 91025

France

Jean-Pierre Schermann

Department of Biophysics and Biochemical Chemistry, WCU, Seoul National University, Seoul 151-147, S. Korea and Laboratoire de Physique des Lasers, Institut Galilée, Université Paris 13, Villetaneuse 93430

France 


\begin{abstract}
Negative ions of copper-aspartic acid $\mathrm{Cu}(\mathrm{Asp})^{-}$and its hydrated complexes have been produced in the gas phase and studied by anion photoelectron spectroscopy. The vertical detachment energies (VDE) of $\mathrm{Cu}(\mathrm{Asp})^{-}$and $\mathrm{Cu}(\mathrm{Asp})^{-}\left(\mathrm{H}_{2} \mathrm{O}\right)_{1,2}$ were determined to be $1.6,1.95$ and $2.20 \mathrm{eV}$, respectively. The spectral profiles of $\mathrm{Cu}$ (Asp) $)^{-}\left(\mathrm{H}_{2} \mathrm{O}\right)_{1}$ and $\mathrm{Cu}(\mathrm{Asp})^{-}\left(\mathrm{H}_{2} \mathrm{O}\right)_{2}$ closely resembled that of $\mathrm{Cu}$ (Asp) ${ }^{-}$, indicating that hydration had not changed the structure of $\mathrm{Cu}(\mathrm{Asp})^{-}$significantly. The successive shifts to higher electron binding energies by the spectra of the hydrated species provided measures of their stepwise solvation energies. Density functional calculations were performed on anionic $\mathrm{Cu}(\mathrm{Asp})^{-}$and on its corresponding neutral. The agreement between the calculated and measured VDE values implied that the structure of the $\mathrm{Cu}(\mathrm{Asp})^{-}$complex originated with a zwitterionic form of aspartic acid in which a copper atom had inserted into the $\mathrm{N}-\mathrm{H}$ bond.
\end{abstract}




\section{Introduction}

Interactions of transition metal with proteins play crucial roles in many metabolic processes. Among these, metal cation-amino acid interactions are particularly important. For this reason, gas-phase metal-amino acid cationic complexes have been widely studied as model systems. ${ }^{1-7}$ Both experimental and theoretical studies have been conducted on transition metal cations, e.g., $\mathrm{Ni}^{+}, \mathrm{Cu}^{+}$and $\mathrm{Ag}^{+}$, bound to glycine, diglycine and triglycine, as have such studies on $\mathrm{Na}^{+}$with aspartic acid, glycine, proline, glutamic acid, asparagine and glutamine. By contrast, both experimental and theoretical studies on gas-phase metal amino acid anions are scarce.

In the present work, we have generated copper-aspartic acid anions and their hydrated species (up to 2 water molecules) and have recorded their photoelectron spectra. Interpretation of these results was conducted by means of density functional theory (DFT) calculations. Using previous computational studies on aspartic acid ${ }^{8,9}$ and on copper $^{10}$ as guidance, we determined the structure of the experimentally observed anionic complex, $\mathrm{Cu}(\mathrm{Asp})^{-}$. Agreement between the calculated and measured VDE values for this species authenticated the computational results. In these complexes, the negative charge is localized mainly on copper, i.e., we studied the interaction between copper anion and neutral aspartic acid counterpart.

\section{Methods}

\section{Experimental}


Negative ion photoelectron spectroscopy is conducted by crossing a mass-selected beam of negative ions with a fixed frequency photon beam and energy analyzing the resultant photodetached electrons. This technique is governed by the energy-conserving relationship $\mathrm{h} v=\mathrm{EKE}+\mathrm{EBE}$, where $\mathrm{h} v$ is the photon energy, EKE is the measured electron kinetic energy, and EBE is the electron binding energy. The present photoelectron spectra were measured with $3.493 \mathrm{eV}$ photons (third harmonic of a Nd:YAG laser) and calibrated against the spectrum of $\mathrm{Cu}^{-}$. A detailed description of the apparatus has been reported elsewhere. ${ }^{11}$

Parent anions of copper-aspartic acid and its hydrated analogs were prepared in a laser vaporization source in which aspartic acid powder had been pressed into a thin layer on the surface of a copper rod. The second harmonic $(532 \mathrm{~nm})$ of a Nd:YAG laser was used to ablate the coated rod, while the rod was simultaneously rotating and translating. Helium gas at 4 bar was injected from a pulsed valve located immediately behind the source for cooling and transporting of the ions. For producing the hydrated species, a small amount of water was placed in the pulsed valve itself; the water vapor seeded the helium gas. The resultant anions then entered a linear time-of-flight mass spectrometer for mass analysis and selection. Thereafter, a second Nd:YAG laser was used for photodetachment, and a magnetic bottle was utilized for electron energy analysis.

\section{Theoretical}

DFT calculations were carried out using the B3LYP ${ }^{12-15}$ density functional, as 
implemented in the Gaussian-03 set of programs. ${ }^{16}$ Full optimizations without any symmetry constraints were first carried out with the $6-311 \mathrm{G}(\mathrm{d})$ basis set. ${ }^{17-19}$ The most stable structures were then re-optimized at the B3LYP/6-31++G(d,p) level of theory. Harmonic vibrational frequencies were also estimated at this level to classify the stationary points as local minima or saddle points, and to estimate the zero-point vibrational energy (ZPE) corrections. Globally, changing the basis set did not lead to substantial structural differences. In order to compute vertical electron detachment energies (VDE) of $\mathrm{Cu} / \mathrm{Asp}$ anionic complexes, further single-point calculations were performed at the B3LYP/6-311++G(3df,2p) level using the geometries obtained with B3LYP/6-31++G(d,p). ZPE corrections were employed only for the optimized anion, since VDE calculations do not require the neutral forms to be optimized. VDE were calculated as the energy difference between the optimized anion and its corresponding neutral at the structure of the anion. Owing to the fact that substantial (and adequate) number of isomers were explored during the initial stages of this study, we were able to extensively explore the potential energy surface in our search for the global minimum. Finally, to give a picture of the distribution of charge within the different species, we have carried out a natural population analysis (NPA) at the B3LYP/6-31G(d,p) level by means of the Natural Bond Orbital (NBO) program. ${ }^{20}$

\section{Results \& Discussion}

Anion photoelectron spectra of $\mathrm{Cu}(\mathrm{Asp})^{-}, \quad \mathrm{Cu}(\mathrm{Asp})^{-}\left(\mathrm{H}_{2} \mathrm{O}\right)_{1}$, and $\mathrm{Cu}(\mathrm{Asp})^{-}\left(\mathrm{H}_{2} \mathrm{O}\right)_{2}$ are presented in Figure 1. The spectrum of $\mathrm{Cu}(\mathrm{Asp})^{-}$shows a broad 
band starting at $\mathrm{EBE}=0.9 \mathrm{eV}$ and reaching an intensity maximum at $\mathrm{EBE}=1.6 \mathrm{eV}$. This latter value corresponds to the VDE of the $\mathrm{Cu}(\mathrm{Asp})^{-}$anion. The VDEs of $\mathrm{Cu}(\mathrm{Asp})^{-}\left(\mathrm{H}_{2} \mathrm{O}\right)_{1}$ and $\mathrm{Cu}(\mathrm{Asp})^{-}\left(\mathrm{H}_{2} \mathrm{O}\right)_{2}$ are $1.95 \mathrm{eV}$ and $2.20 \mathrm{eV}$, respectively. The spectral profiles of $\mathrm{Cu}(\mathrm{Asp})^{-}\left(\mathrm{H}_{2} \mathrm{O}\right)_{1}$ and $\mathrm{Cu}(\mathrm{Asp})^{-}\left(\mathrm{H}_{2} \mathrm{O}\right)_{2}$ closely resemble that of $\mathrm{Cu}(\mathrm{Asp})^{-}$, indicating that hydration has not changed the structure of $\mathrm{Cu}(\mathrm{Asp})^{-}$ significantly; $\mathrm{Cu}(\mathrm{Asp})^{-}$is the chromophore. The successive shifts to higher electron binding energies by the spectra of the hydrated species provide measures of their stepwise hydration energies. The shift between the VDE of $\mathrm{Cu}(\mathrm{Asp})^{-}$and that of $\mathrm{Cu}$ (Asp) $)^{-}\left(\mathrm{H}_{2} \mathrm{O}\right)_{1}$ is $0.35 \mathrm{eV}$, while the shift between the VDE of $\mathrm{Cu}(\mathrm{Asp})^{-}\left(\mathrm{H}_{2} \mathrm{O}\right)_{1}$ and that of $\mathrm{Cu}(\mathrm{Asp})^{-}\left(\mathrm{H}_{2} \mathrm{O}\right)_{2}$ is $0.25 \mathrm{eV}$. Thus, $0.35 \mathrm{eV}$ is an estimate of the energy gained when $\mathrm{Cu}(\mathrm{Asp})^{-}$is solvated by a single water molecule, and $0.25 \mathrm{eV}$ is an estimate of the energy gained when $\mathrm{Cu}(\mathrm{Asp})^{-}\left(\mathrm{H}_{2} \mathrm{O}\right)_{1}$ is solvated by an additional water molecule.

Several initial geometries were investigated in order to obtain a complete set of optimized anionic $\mathrm{Cu}(\mathrm{Asp})^{-}$structures, and these are shown in Figure 2. The copper atom interacts with either canonical or zwitterionic aspartic acid, and in subsequent figures the optimized structures are labeled as $\mathbf{C x}$, and $\mathbf{Z x}$, respectively. For the initial geometries with the copper atom interacting with both carboxylic groups, the optimization did not reach completion because the molecule started to dissociate during the process. The energies of those partially optimized structures are higher than those of the other structures. The results for the most stable structures are reported in Table 1 and Figure 3. There are two different families of structures: those in which the copper atom is inserted in a $\mathrm{C}-\mathrm{X}$ or $\mathrm{X}-\mathrm{H}$ bond $(\mathrm{X}=\mathrm{O}$ or $\mathrm{N})$ and those in where the 
copper is not bonded between two atoms. Inserted structures include C1, C2, C3, C4, $\mathbf{C 5}, \mathbf{Z 1}$, and $\mathbf{Z 2}$ illustrated in Figure 3 and listed in Table 1. Non-inserted structures are not shown here, since they are less stable by more than $1.8 \mathrm{eV}$, and therefore, they are not likely to have been generated in the beam. Table 1 shows that, at the highest level of calculation, there are six particularly stable structures lying within $0.085 \mathrm{eV}$ of one another. In all of these, the copper atom is inserted into a N-H $(\mathbf{Z 1})$ or O-H (C1-C5) bond. Insertion of the copper into a $\mathrm{C}-\mathrm{N}$ bond results in a less stable structure $(\mathbf{Z 2})$ by $0.501 \mathrm{eV}$. Note that $\mathbf{C 3}$ and $\mathbf{C 5}$ are similar in structure. The difference is only a small rotation of the amino group, with $\mathbf{C 5}$ being slightly more stable than C3. For this reason, the further discussion will not include C3. The results reported in Table 1 show that the order of the stability depends on the basis set that was used during the optimization. $\mathbf{Z 1}$ is the most stable structure at the B3LYP/6-31++G(d,p) level, while C5 becomes the global minimum at B3LYP/6-311++G(3df,2p) level. However, the energy difference between these structures is very small and is within the uncertainties of the calculation.

While it is difficult to determine which structure would be observed experimentally from the total energies results alone, the calculated VDE value of each structure is different and comparison with the experimentally-measured VDE value allows us to determine which one was actually observed. For structures with the copper atom inserted into O-H (C1 to C5), the computed VDE values lie between 1.12 to $1.35 \mathrm{eV}$ at the highest level of theory. The calculated VDE value of structure, $\mathbf{Z 1}$ is $1.74 \mathrm{eV}$, which is in excellent agreement with the experimental result $(\sim 1.6 \mathrm{eV})$. 
Thus, we conclude that a zwitterionic form of aspartic acid with a copper atom inserted into the $\mathrm{N}-\mathrm{H}$ bond, i.e., $\mathbf{Z 1}$, is the dominant species generated in the experiment. As mentioned above, there is evidence that solvating the $\mathrm{Cu}(\mathrm{Asp})^{-}$ complex with water molecules did not change the structure of $\mathrm{Cu}(\mathrm{Asp})^{-}$, i.e., it can be expected to maintain its zwitterionic structure upon hydration.

The theoretical results also provided additional information about the anionic $\mathrm{Cu}(\text { Asp) })^{-}$complexes. Among the $\mathrm{O}-\mathrm{H}$ inserted $\mathbf{C x}$ structures, these are uniformly more stable than either the $\mathrm{N}-\mathrm{H}$ insertion structures or the $\mathrm{C}-\mathrm{X}$ inserted forms. For zwitterionic $\mathrm{Cu}(\mathrm{Asp})^{-}$structures, $\mathbf{Z x}$, the $\mathrm{N}-\mathrm{H}$ inserted form $(\mathbf{Z 1})$ is remarkably more stable than others. A copper atom inserted into the $\mathrm{O}-\mathrm{H}$ bond of a zwitterionic structure does not correspond to a stable form.

Furthermore, Figure 3 also shows that the most stable structures have an intramolecular hydrogen bond between the carboxylic groups. The $\mathrm{O}-\mathrm{H}$ bond length clearly depends on the strength of the hydrogen bond. With second order perturbation theory analysis using the NBO code, ${ }^{19}$ it is possible to estimate the strength of these interactions by calculating the corresponding stabilization energy. If one considers $\mathbf{C 1}$ for example, the $\mathrm{E}\left[\mathrm{LP}_{\mathrm{O}(3)^{-}} \sigma^{*} \mathrm{O}(4)-\mathrm{H}\right]$ interaction energy is equal to $245.7 \mathrm{~kJ} / \mathrm{mol}$. The $\mathrm{O}(3)-\mathrm{H}$ hydrogen bond is strong and, as a consequence, the $\mathrm{O}(4)-\mathrm{H}$ chemical bond is elongated to $1.027 \AA$ (the normal O-H chemical bond length at this level of theory is $0.98 \AA$ ). For $\mathbf{C 5}$ and $\mathbf{Z 1}$, the hydrogen bond is even stronger, as attested by the $\mathrm{E}\left[\mathrm{LP}_{\mathrm{O}(4)^{-}} \sigma^{*} \mathrm{O}(3)-\mathrm{H}\right]$ and $\mathrm{E}\left[\mathrm{LP}_{\mathrm{O}(3)^{-}} \sigma^{*} \mathrm{O}(4)-\mathrm{H}\right]$ interaction energies, which are 296.2 and $354.5 \mathrm{~kJ} / \mathrm{mol}$ for $\mathbf{C 5}$ and $\mathbf{Z 1}$, respectively. The $\mathrm{O}-\mathrm{H}$ chemical bond length therefore 
increases accordingly. In fact, $\mathbf{C 1}, \mathbf{C 5}$ (very similar to $\mathbf{C 3}$ ), and $\mathbf{Z 1}$ have the strongest hydrogen bonds among all the structures and are stabilized by these hydrogen bonds. This explains why they are also the most stable ones in energy. In addition, the NBO study also indicates that hydrogen bonds involving the amino group are much weaker. The $\mathrm{E}\left[\mathrm{LP}{\mathrm{O}(2)^{-}} \sigma^{*} \mathrm{~N}(1)-\mathrm{H}\right]$ interaction energies are equal to 11.5 and $32.8 \mathrm{~kJ} / \mathrm{mol}$ for $\mathbf{C 1}$ and $\mathbf{Z 1}$, respectively, while for $\mathbf{C 5}$ there is no hydrogen bond between $\mathrm{N} 1(\mathrm{H})$ and $\mathrm{O}(2)$. For $\mathbf{Z 1}$, the elongation of the $\mathrm{N}(1)-\mathrm{H}$ bond is essentially due to the interaction of the nitrogen atom with the copper atom. Furthermore, the NBO analysis also gives some insights about the interaction between the copper atom and the aspartic acid. The bond can be described as the electrostatic association of a deprotonated aspartic acid interacting with a copper hydride moiety. A covalent bond is indeed found between the copper and the hydrogen atom. Molecular Orbitals of the most stable anionic form, $\mathbf{Z 1}$, can be found in Figure 5. Its HOMO orbital is degenerate and corresponds to a non-bonding d orbital of the copper atom. This indicates that the extra electron is located on the copper atom. The HOMO-1 orbital of $\mathbf{Z 1}$ shows a sigma $\mathrm{Cu}-\mathrm{H}$ bonding orbital, corroborating the idea of the covalent bond. The Molecular Orbitals for other stable anionic structures are found to be similar.

To give a picture of the charge distribution within the complexes, we have carried out a natural population analysis (NPA) at the B3LYP/6-31++G(d,p) level. For anionic complexes, the natural charge on the copper atom ranges from 0.38 to 0.45 for all the structures. Removal of an electron without relaxing the geometry of the systems (vertical transition) significantly modifies the natural charges. The most 
important variation is observed for the copper atom, whose natural charge becomes 0.99, 1.03, and 0.82 for $\mathbf{C 1}, \mathbf{C 5}$, and $\mathbf{Z 1}$, respectively. Correspondingly, the negative charge of the hydrogen atom bound to the copper atom decreases slightly to -0.54 . This indicates that some of the anion's excess electron is delocalized over the larger complex, and it further supports the assumption of a copper hydride moiety. One also notices that for the anionic $\mathrm{Cu}(\mathrm{Asp})^{-}$complexes, the positively-charged copper metal atom interacts with two negatively-charged atoms $(\mathrm{N}$ and $\mathrm{H}$ in the case of $\mathbf{Z 1}$ or $\mathrm{O}$ and $\mathrm{H}$ in the case of C1-C5). This contributes to the stabilization of the inserted compounds.

Starting from the most stable anionic structures: $\mathbf{C 1}, \mathbf{C 5}$, and $\mathbf{Z 1}$, the relaxed geometries of their corresponding neutral complexes have also been calculated. These structures are labeled $\mathbf{N}_{\mathbf{C} 1}, \mathbf{N}_{\mathbf{C 5}}$, and $\mathbf{N}_{\mathbf{Z 1}}$, respectively and are depicted in Figure 4, along with their relative energies. Interestingly, their structures differ significantly from those of their anionic counterparts. In the anionic structures, the copper atoms are strongly bonded to two atoms in a linear arrangement, a fact that seems well-established for $\mathrm{Cu}(\mathrm{I})$ ionic complexes. ${ }^{21}$ However, upon removal of an electron from $\mathbf{C 1}$ and from $\mathbf{C 5}$ (followed by geometry relaxation), the resultant neutral structures, $\mathbf{N}_{\mathbf{C} 1}$ and $\mathbf{N}_{\mathbf{C 5}}$, are found to have acquired an additional (albeit weak) interaction with the copper atom. By contrast, however, $\mathbf{N}_{\mathbf{Z 1}}$ does not gain an additional weak bonding interaction; it simply remains a bidentate structure. One notices that the differences in energies between these neutral forms are greater than the differences in energies between their corresponding anionic forms. This is the 
reason for the variation in computed VDE values for the different structures. The Molecular Obitals of the neutral $\mathbf{N}_{\mathbf{C 5}}$ is shown in Figure 5. Its SOMO is degenerate and located on the aspartic acid molecule, whilst the SOMO-1 is a sigma $\mathrm{Cu}-\mathrm{H}$ bonding orbital.

\section{Acknowledgements}

The experimental part of this material (K.H.B.) is based on work supported by the US National Science Foundation under Grant No. CHE-0809258. The theoretical part of this study (A.M.) was made possible due to funding by DGAPA-PAPIIT (grant no. IN124602-3), Consejo Nacional de Ciencia y Tecnología CONACyT (grant no. 222506), and resources provided by the Instituto de Investigaciones en Materiales IIM. Some of the calculations were carried out using a KanBalam supercomputer, provided by DGSCA, UNAM. Part of this work (J.P.S.) was conducted with the support of the World Class University Project supported by the Ministry of Education, Science and Technology of Korea. 


\section{References}

1. C. Kapota, J. Lemaire, P. Maitre, G. Ohanessian, J. Am. Chem. Soc. 126, 1836 (2004).

2. Principles of Mass Spectrometry Applied to Biomolecules, John Wiley \& Sons, Hoboken, 2006.

3. F. Tureček, Mass Spectrom. Rev. 26, 563 (2007).

4. P.B. Armentrout, A. Gabriel, R.M. Moision, Int. J. Mass Spectrom. 283, 56 (2009).

5. L. Rodriguez-Santiago, M. Sodupe, and J. Tortajada, J. Phys. Chem. A 105, 5340 (2001).

6. M. K. Kim, and A. E. Martell, J. Amer. Chem. Soc. 91, 872 (1969).

7. M. Massaoutia, and M. Velegrakis, Int. J. Mass Spectrom. 225, 89 (2003).

8. P.S. Kushwaha, P.C. Mishra, J. Mol. Struct.-Theochem 549, 229 (2001).

9. W. Sang-Aroon, V. Ruangpornvisuti, J. Mol. Struct.-Theochem 758, 181 (2006).

10. G. Alagona, C. Ghio, Phys. Chem. Chem. Phys. 11, 776 (2009).

11. M. Gerhards, O. C. Thomas, J. M. Nilles, W.-J. Zheng, K. H. Bowen: J. Chem. Phys. 116, 10247 (2002).

12. B. Miehlich, A. Savin, H. Stoll, H. Preuss, Chem. Phys. Lett. 157, 200 (1989).

13. R.M. Dickson, A.D. Becke, J. Chem. Phys. 99, 3898 (1993).

14. A.D. Becke, J. Chem. Phys. 98, 5648 (1993).

15. A.D. Becke: J. Chem. Phys. 98, 1372 (1993).

16. M.J. Frisch, G.W. Trucks, H.B. Schlegel, G.E. Scuseria, M.A. Robb, J.R. 
Cheeseman, V.G. Zakrzewski, J. J. A. Montgomery, T. Vreven, K.N. Kudin, J.C. Burant, J.M. Millam, S.S. Iyengar, J. Tomasi, V. Barone, B. Mennucci, M. Cossi, G. Scalmi, N. Rega, G.A. Petersson, H. Nakatsuji, M. Hada, M. Ehara, K. Toyota, R. Fukuda, J. Hasegawa, M. Ishida, T. Nakajima, Y. Honda, O. Kitao, C. Adamo, J. Jaramillo, R. Gomperts, R.E. Stratmann, O. Yazyev, J. Austin, R. Cammi, C. Pomelli, J. Ochterski, P.Y. Ayala, K. Morokuma, G.A. Voth, P. Salvador, J.J. Dannenberg, V.G. Zakrzewski, S. Dapprich, A.D. Daniels, M.C. Strain, O. Farkas, D.K. Malick, A.D. Rabuck, K. Raghavachari, J.B. Foresman, J.V. Ortiz, Q. Cui, A.G. Baboul, S. Clifford, J. Cioslowski, B.B. Stefanov, G. Liu, A. Liashenko, P. Piskorz, I. Komaromi, R.L. Martin, D.J. Fox, T. Keith, M.A. Al-Laham, C.Y. Peng, A. Nanayakkara, M. Challacombe, P.M.W. Gill, B. Johnson, W. Chen, M.W. Wong, C. Gonzalez, J.A. Pople, Gaussian03. revision B.05. Gaussian, Inc., Wallingford CT, 2003.

17. A.D. McLean, G.S. Chandler, J. Chem. Phys. 72, 5639 (1980).

18. R. Krishnan, J.S. Binkley, R. Seeger, J.A. Pople, J. Chem. Phys. 72, 650 (1980).

19. T. Clark, J. Chandrasekhar, G.W. Spitznagel, P.V. Schleyer, J. Comput. Chem. 4, 294 (1983).

20. E.D. Glendening, A.E. Reed, F. Weinhold, NBO version 3.1.

21. A.M. Lamsabhi, M. Yáñez, J.-Y. Salpin, J. Tortajada, Gas-Phase Chemistry of Organocopper Compounds, John Wiley \& Sons, Chichester, 2009. 


\section{Figure Captions:}

Figure 1. The photoelectron spectra of $\mathrm{Cu}(\mathrm{Asp})^{-}, \mathrm{Cu}(\mathrm{Asp})^{-}\left(\mathrm{H}_{2} \mathrm{O}\right)_{1}$, and $\mathrm{Cu}(\text { Asp })^{-}\left(\mathrm{H}_{2} \mathrm{O}\right)_{2}$, all recorded at photon energies of $3.493 \mathrm{eV}$.

Figure 2. Initial geometries considered for the $\mathrm{Cu}(\mathrm{Asp})^{-}$complex

Figure 3. Most stable optimized structures of $\mathrm{Cu}(\mathrm{Asp})^{-}$. Relative energies $(\mathrm{eV})$ determined at the B3LYP/6-311++G(3df,2p)//B3LYP/6-31++G(d,p)+ZPE level are given in parentheses. Most important bond distances are given in italics (in $\AA$ ). All the anions are in their singlet states.

Figure 4. Optimized structures of $\mathrm{Cu}(\mathrm{Asp})$ neutral forms corresponding to anionic C1, $\mathbf{C 5}$ and $\mathbf{Z 1}$ forms. B3LYP/6-311++G(3df,2p)//B3LYP/6-31++G(d,p)+ZPE relative energy values (in $\mathrm{eV}$ ) are given in parentheses. Most important bond distances are given in italics (in $\AA$ ). All the neutrals are in their doublet states.

Figure 5. Most representative Molecular Orbitals of $\mathrm{Cu}(\mathrm{Asp})$ (anionic $\mathbf{Z 1}$ and neutral $\mathbf{N}_{\mathbf{C 5}}$ forms). 


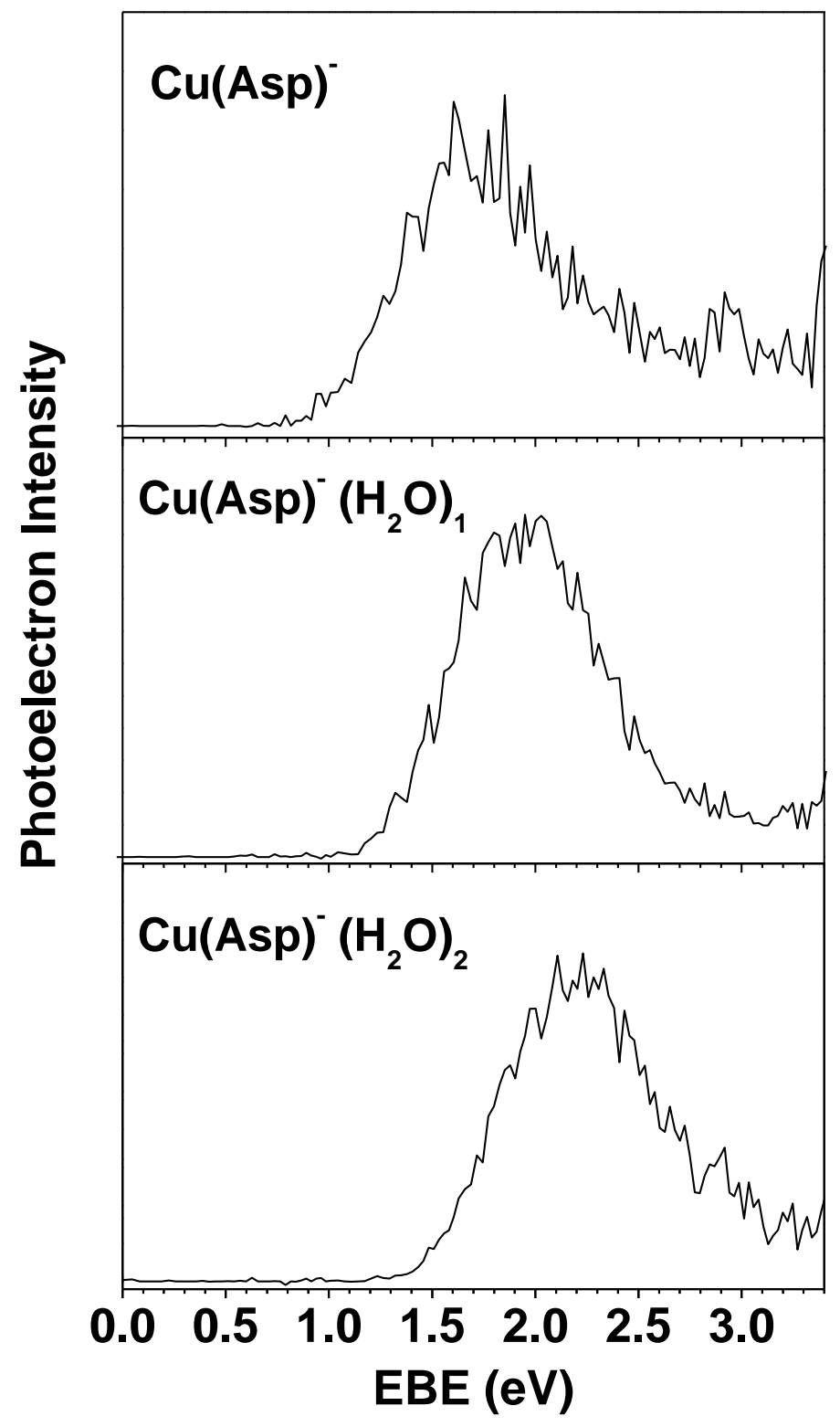

Figure 1. 
Structures based on canonical aspartic acid<smiles></smiles><smiles></smiles><smiles></smiles><smiles></smiles><smiles>NNC(CC(=O)C(N)CC(=O)OO)C(=O)OO</smiles><smiles>O=C(O)CC(NO)C(=O)O</smiles><smiles>NC(CC(=O)O)C(=O)O</smiles><smiles>NC(CC(=O)OO)C(=O)O</smiles>

Structures based on zwitterionic aspartic acid<smiles>[NH3+]C(CC(=O)O)c1o[c-]([OH2+])[o+]1</smiles><smiles></smiles><smiles>NC(CC(=O)O)C(=O)[O-]</smiles><smiles>NC(CC(=O)[O-])C([O-])=[OH+]</smiles><smiles>O=C([O-])CC([18OH])C(=O)O</smiles><smiles>O=C(O)CC([18O]O)C(=O)[O-]</smiles><smiles>[NH3+]OCC(CC(=O)O)C(=O)[O-]</smiles><smiles>O=C(O)CC1[N]C2OC([O-])=C([O-])C12</smiles><smiles>O=C[N]C(CC(=O)O)C(=O)[O-]</smiles><smiles>[NH3+]OCC(CC(=O)[O-])C(=O)O</smiles>

Figure 2. 


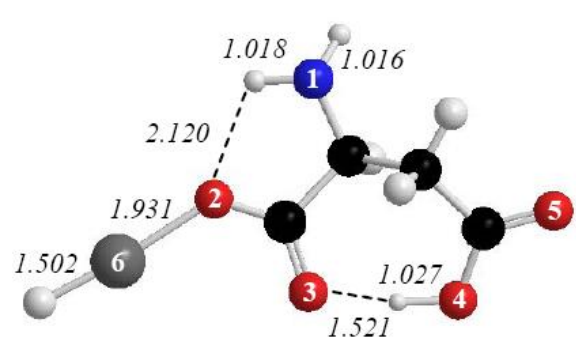

C1 (0.004)

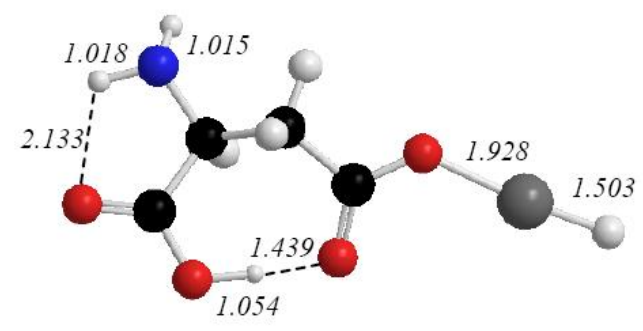

C3 (-0.005)

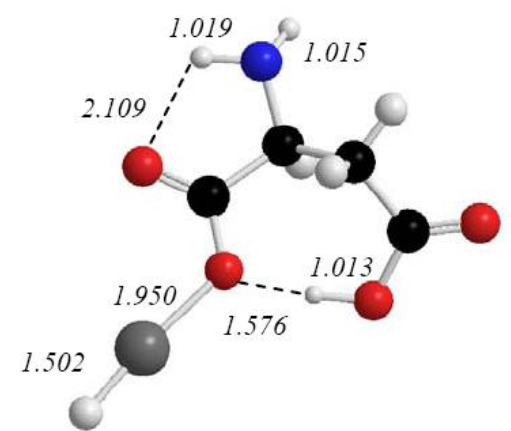

C2 (0.085)

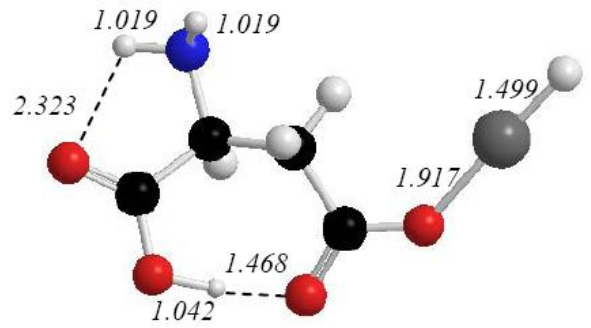

C4 (0.011)

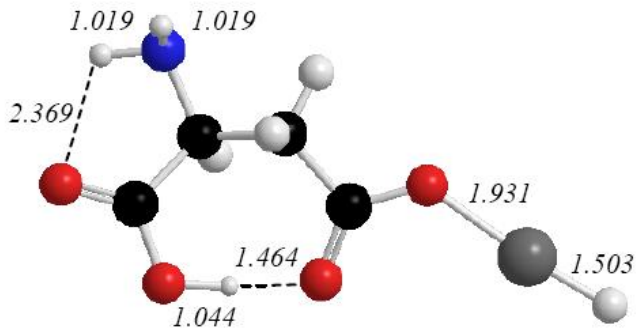

C5 $(-0.012)$

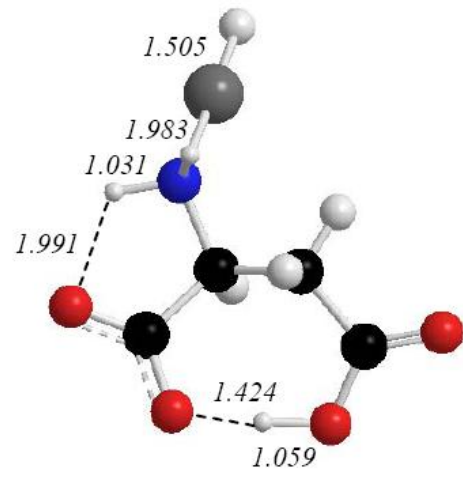

Z1 (0.000)

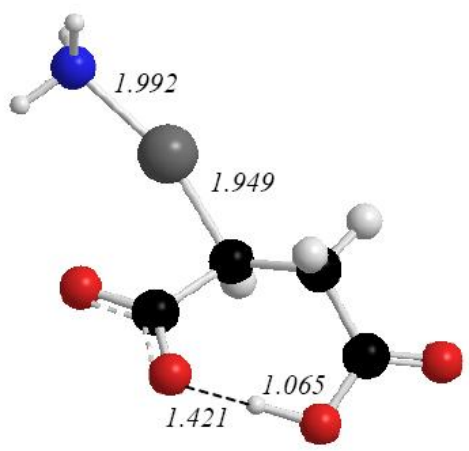

Z2 (0.501)

Figure 3. 


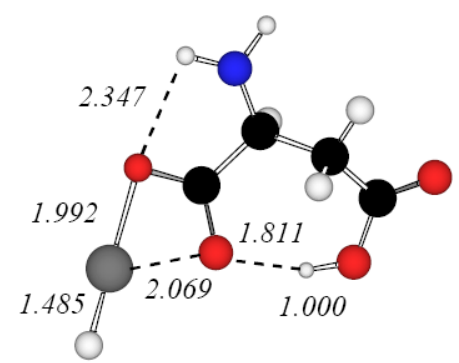

$N_{C_{1}}(0.107)$

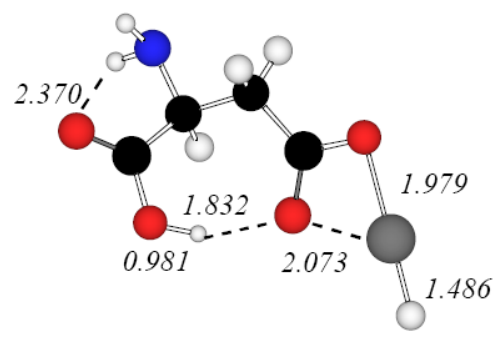

$\mathrm{N}_{\mathrm{c5}}(0.000)$

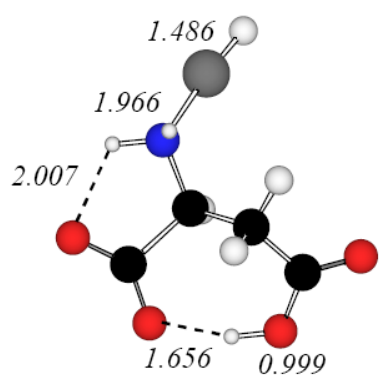

$N_{z 1}(1.069)$

Figure 4. 


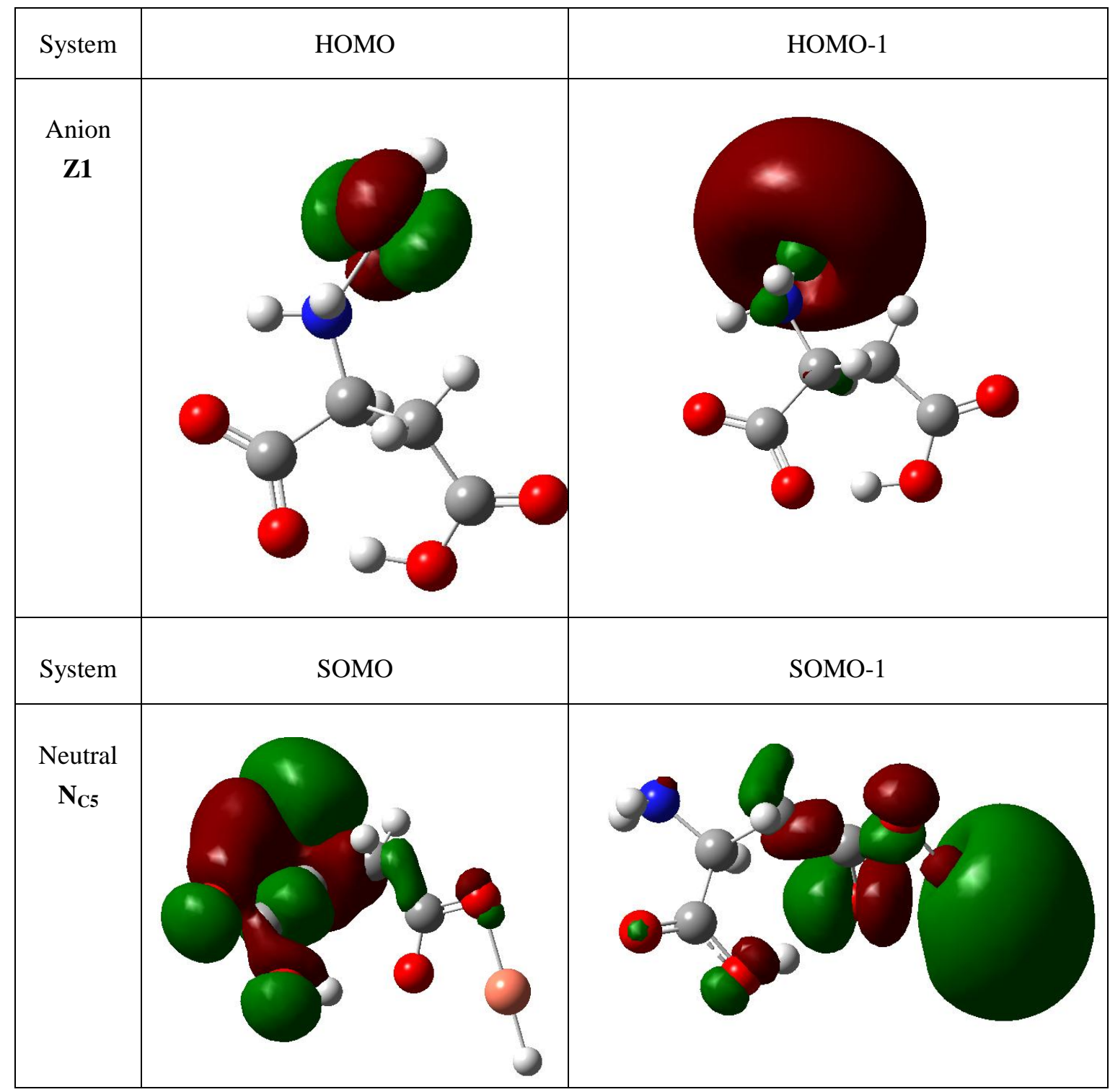

Figure 5 


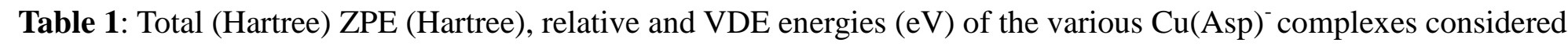

\begin{tabular}{|c|c|c|c|c|c|c|c|c|}
\hline \multirow[b]{2}{*}{ Structure } & \multirow[b]{2}{*}{ Binding of $\mathrm{Cu}$ atom } & \multicolumn{4}{|c|}{ B3LYP/6-31++G(d,p) } & \multicolumn{3}{|c|}{ B3LYP/6-311++G(3df,2p) ${ }^{a}$} \\
\hline & & $\mathrm{E}$ & $\mathrm{ZPE}$ & $\begin{array}{c}\Delta \mathrm{E} \\
(\mathrm{eV})\end{array}$ & $\begin{array}{l}\text { VDE } \\
(\mathrm{eV})\end{array}$ & $\mathrm{E}$ & $\Delta \mathrm{E}(\mathrm{eV})$ & $\begin{array}{l}\text { VDE } \\
(\mathrm{eV})\end{array}$ \\
\hline $\mathrm{C1}$ & inserted into $\mathrm{O}-\mathrm{H}$ bond & -2152.820930 & .118006 & 0.027 & 1.26 & -2153.137741 & 0.004 & 1.20 \\
\hline $\mathrm{C2}$ & inserted into $\mathrm{O}-\mathrm{H}$ bond & -2152.818324 & .118132 & 0.101 & 1.16 & -2153.134889 & 0.085 & 1.13 \\
\hline $\mathrm{C3}$ & inserted into $\mathrm{O}-\mathrm{H}$ bond & -2152.820259 & .117221 & 0.024 & 1.17 & -2153.137293 & -0.005 & 1.16 \\
\hline $\mathrm{C4}$ & inserted into $\mathrm{O}-\mathrm{H}$ bond & -2152.819912 & .117501 & 0.041 & 1.40 & -2153.136995 & 0.011 & 1.35 \\
\hline C5 & inserted into $\mathrm{O}-\mathrm{H}$ bond & -2152.821293 & .117634 & 0.007 & 1.20 & -2153.137981 & -0.012 & 1.12 \\
\hline $\mathbf{Z 1}$ & inserted into $\mathrm{N}-\mathrm{H}$ bond & -2152.822267 & .118350 & 0.000 & 1.84 & -2153.138242 & 0.000 & 1.74 \\
\hline $\mathbf{Z 2}$ & inserted into $\mathrm{C}-\mathrm{N}$ bond & -2152.805317 & .118769 & 0.473 & $\mathrm{~b}$ & -2153.120257 & 0.501 & $\mathrm{~b}$ \\
\hline
\end{tabular}

${ }^{\mathrm{a}}$ Obtained with the B3LYP/6-31++G(d,p) geometries

${ }^{\mathrm{b}}$ These values are not included since this structure is less stable and it is not expected in the experiment 